Annals of Surgery

DOI: $10.1097 /$ SLA.0000000000005070

\title{
Optimal Timing of Administration of Direct-Acting Antivirals for Patients with Hepatitis C-Associated Hepatocellular Carcinoma Undergoing Liver Transplantation
}

Michael K. Turgeon, MD ; Shimul A. Shah, MD, MHCM ${ }^{2}$; Aaron M. Delman, MD ${ }^{2}$; Benjamin V. Tran, MD³; Vatche G. Agopian, MD³; Joel P. Wedd, MD, MPH ${ }^{1}$; Joseph F. Magliocca, $\mathrm{MD}^{1}$; Ahyoung Kim, $\mathrm{MD}^{4}$; Andrew Cameron, $\mathrm{MD}, \mathrm{PhD}^{4}$; Ali Olyaei, $\mathrm{PharmD}^{5}$; Susan L. Orloff, MD ${ }^{5}$; Matthew P. Anderson, BS ${ }^{6}$; Chandrashekhar A. Kubal, MD, PhD ${ }^{6}$; Robert M. Cannon, $\mathrm{MD}^{7}$; Jayme E. Locke MD, MPH${ }^{7}$; Mary A. Simpson, $\mathrm{PhD}^{8}$; Mohamed E. Akoad, $\mathrm{MD}^{8}$; Chelsey P. Wongjirad, $\mathrm{DO}^{9}$; Juliet Emamaullee, $\mathrm{MD}, \mathrm{PhD}^{9}$; Amika Moro, $\mathrm{MD}^{10}$; Federico Aucejo, MD ${ }^{10}$; Cyrus A. Feizpour, MD ${ }^{11}$; Parsia A. Vagefi, MD ${ }^{11}$; Mindie H. Nguyen, $\mathrm{MD}, \mathrm{MAS}^{12}$; Carlos O. Esquivel, $\mathrm{MD}, \mathrm{PhD}^{12}$; Kiran Dhanireddy, $\mathrm{MD}^{13}$; Vijay Subramanian, $\mathrm{MD}^{13}$; Alejandro Chavarriaga, $\mathrm{MD}^{14}$; Marwan M. Kazimi, MD ${ }^{14}$; Maia S. Anderson, $\mathrm{MD}^{15}$; Christopher J. Sonnenday, $\mathrm{MD}^{15}$; Steven C. Kim, MD ${ }^{16}$; David P. Foley, $\mathrm{MD}^{16}$; Marwan Abdouljoud, $\mathrm{MD}^{17}$; Reena J. Salgia, $\mathrm{MD}^{17}$; Dimitrios Moris, MD, $\mathrm{PhD}^{18}$; Debra L. Sudan, MD ${ }^{18}$; Swaytha R. Ganesh, MD ${ }^{19}$; Abhinav Humar, MD ${ }^{19}$; Majella Doyle, $\mathrm{MD}^{20}$; William C. Chapman, $\mathrm{MD}^{20}$; Shishir K. Maithel, MD ${ }^{1}$

1. Emory University, Atlanta, GA

2. University of Cincinnati College of Medicine, Cincinnati, $\mathrm{OH}$

3. David Geffen School of Medicine at UCLA, Los Angeles, CA

4. Johns Hopkins, Baltimore, MD

5. Oregon Health and Science University, Portland, OR

6. Indiana University Health, Indianapolis, IN

7. University of Alabama at Birmingham, Birmingham, AL

8. Lahey Hospital and Medical Center, Boston, MA

9. Keck Hospital of University of Southern California, Los Angeles, CA

10. Cleveland Clinic, Cleveland, $\mathrm{OH}$

11. UT Southwestern Medical Center, Dallas, TX

12. Stanford University Medical Center, Palo Alto, CA

13. Tampa General Hospital, Tampa, FL

14. Piedmont Healthcare, Atlanta, GA

15. University of Michigan, Ann Arbor, MI

16. University of Wisconsin School of Medicine and Public Health, Madison, WI

17. Henry Ford Health System, Detroit, MI

18. Duke University School of Medicine, Durham, NC

19. University of Pittsburgh Medical Center, Pittsburgh, PA

20. Washington University School of Medicine at St. Louis, St. Louis, MO 


\section{Contact Information:}

Michael K. Turgeon, MD

Katz Foundation Research Fellow

Winship Cancer Institute, Division of Surgical Oncology

Department of Surgery, Emory University

1365 Clifton Road, NE; Building B, Suite 4100, Office 4201

Atlanta, GA 30322

mturgeo@emory.edu

Phone: 404-921-4280

Fax: 404-778-4255

\section{Corresponding Author:}

Shishir K. Maithel, MD, FACS

Professor of Surgery

Scientific Director, Emory Liver and Pancreas Center

Winship Cancer Institute, Division of Surgical Oncology

Department of Surgery, Emory University

1365 Clifton Road, NE; Building B, Suite 4100, Office 4202

Atlanta, GA 30322

smaithe@emory.edu

Phone: 404-778-5777

Fax: 404-778-4255

Ethical Statement: the authors are accountable for all aspects of the work in ensuring that questions related to the accuracy or integrity of any part of the work are appropriately investigated and resolved. 
Disclosures: M. K. Turgeon, None.; S. A. Shah, Veloxis Pharmaceuticals Role(s): Membership on advisory committee or review panels. Organ Recovery Systems Role(s): Other activities (please specify), Research funding.; A. A. Delman, None.; B. V. Tran, None.; V. G. Agopian, None.; J. P. Wedd, None.; J. F. Magliocca, None.; A. Kim, None.; A. Cameron, None.; A Olyaei, None.; S. L. Orloff, None.; M. P. Anderson, None.; C. A. Kubal, None.; R. M. Cannon, None.; J. E. Locke, None.; M. A. Simpson, None.; M. E. Akoad, None.; C. P. Wongjirad, None.; J. Emamaullee, iSPY COVID trial Role(s): Other activities (please specify), Data Monitoring Committee. Gilead Role(s): Other activities (please specify), Research funding. American Society of Transplant Surgeons Role(s): Other activities (please specify), Research funding. American Association for the Study of Liver Diseases Role(s): Other activities (please specify), Research Funding. National Cancer Institute Role(s): Other activities (please specify), Research funding.; A. Moro, None.; F. Aucejo, None.; C. A. Feizpour, None.; P. A. Vagefi, None.; M. H. Nguyen, Gilead Role(s): Other activities (please specify), Research support. Glycotest Role(s): Other activities (please specify), Research support. National Cancer Institute Role(s): Other activities (please specify), Research support. Bayer Role(s): Consulting. Esai Role(s): Consulting. Novartis Role(s): Consulting. Gilead Role(s): Consulting. Exact Sciences Role(s): Consulting. Laboratory of Advanced Medicine Role(s): Consulting.; C. O. Esquivel, None.; K. Dhanireddy, None.; V. Subramanian, None.; A. Chavarriaga, None.; M. M. Kazimi, None.; M. S. Anderson, None.; C. J. Sonneday, None.; S. C. Kim, None.; D. P. Foley, None.; M. Abdouljoud, None.; R. J. Salgia, None.; D. Moris, None.; D. L. Sudan, None.; S. R. Ganesh, None.; A. Humar, None.; M. Doyle, None.; W. C. Chapman, Novartis Role(s): Membership on advisory committee or review panels. Pathfinder Role(s): Other activities (please specify), IP royalties.; S. K. Maithel, Celgene (Bristol Meyers Squibbs)

Financial Support: this study is supported in part by the Katz Foundation and the National Center for Advancing Translational Science (Grant/Award Number: UL1TR002378/TL1TR002382).

Running Head: Optimal Timing: Direct Acting Antivirals

\section{Mini-Abstract:}

The optimal timing of direct acting antivirals (DAAs) for patients with hepatitis C-associated hepatocellular carcinoma undergoing liver transplantation has been a topic of much debate. For interferon treatment-naïve patients undergoing liver transplantation within Milan criteria, initiating DAAs early in the post-operative period was associated with improved rates of sustained virologic response and HCC recurrence-free survival. 


\section{Structured Abstract:}

\section{Objective}

To investigate the optimal timing of direct acting antiviral (DAA) administration in patients with hepatitis $\mathrm{C}$-associated hepatocellular carcinoma (HCC) undergoing liver transplantation

\section{Summary of Background Data}

In patients with hepatitis $\mathrm{C}(\mathrm{HCV})$ associated hepatocellular carcinoma undergoing liver transplantation (LT), the optimal timing of direct-acting antivirals (DAA) administration to achieve sustained virologic response (SVR) and improved oncologic outcomes remains a topic of much debate.

\section{Methods}

The United States HCC Liver Transplantation Consortium (2015-2019) was reviewed for patients with primary $\mathrm{HCV}$-associated $\mathrm{HCC}$ who underwent LT and received DAA therapy at 20 institutions. Primary outcomes were SVR and HCC recurrence-free survival (RFS).

\section{Results}

Of 857 patients, 725 were within Milan criteria. SVR was associated with improved 5-year RFS (92\% vs 77\%, p<0.01). Patients who received DAAs pre-LT, 0-3 months post-LT, and $\geq 3$ months post-LT had SVR rates of $91 \%, 92 \%$, and $82 \%$, and 5 -year RFS of $93 \%, 94 \%$, and $87 \%$, respectively.

Among $427 \mathrm{HCV}$ treatment-naïve patients (no previous interferon therapy), patients who achieved SVR with DAAs had improved 5-year RFS (93\% vs 76\%, p<0.01). Patients who received DAAs pre-LT, $0-3$ months post-LT, and $\geq 3$ months post-LT had SVR rates of 91\%, $93 \%$, and $78 \%(p<0.01)$ and 5 -year RFS of $93 \%, 100 \%$, and $83 \%(p=0.01)$.

\section{Conclusions}

The optimal timing of DAA therapy appears to be 0-3 months after liver transplantation for $\mathrm{HCV}$-associated HCC, given increased rates of SVR and improved RFS. Delayed administration after transplant should be avoided. A prospective randomized controlled trial is warranted to validate these results.

\section{Keywords}

Hepatocellular carcinoma, direct acting antivirals, liver transplant, hepatitis $\mathrm{C}$, recurrence, sustained virologic response 


\section{Introduction}

Hepatitis $\mathrm{C}$ virus $(\mathrm{HCV})$ is the most common cause of hepatocellular carcinoma (HCC) in the United States, affecting 6 per 100,000 individuals each year. ${ }^{1}$ Between 2008 and 2016, the incidence rate of HCC has steadily increased by $3 \%$ annually, with recent projections indicating its continued growth. ${ }^{2}$ This is partly attributable to the high prevalence of $\mathrm{HCV}^{3}$

Historically, the mainstay of treatment for HCV included interferon-based regimens with or without ribavirin. Given a significant adverse drug reaction profile, this regimen had poor adherence, as well as low overall rates of achieving a sustained virologic response (SVR), defined as no detectable virus 12-24 weeks after end of therapy. ${ }^{4}$ Fortunately, the advent of direct acting antivirals (DAAs) in 2011 and subsequent FDA approval of second generation DAAs in 2014 revolutionized the treatment of HCV by offering a well-tolerated and much more efficacious treatment option, with a favorable side-effect profile, which resulted in improved compliance and rates of SVR exceeding $95 \% .5$

Chronic HCV infection leads to hepatic inflammation and fibrosis, conferring an over 20-fold increased risk for developing HCC. ${ }^{6}$ DAAs halt HCV's continuous insult on the liver and may improve liver function, potentially reducing the risk for developing de novo HCC., 8 However, some studies have suggested DAA administration was associated with increased rates of HCC recurrence after curative treatment of HCC. ${ }^{9,}{ }^{10}$ On the other hand, recent larger and well-controlled studies found no significant difference in HCC recurrence in DAAtreated patients, and multi-center studies from both the U.S. and Asia have shown significant survival improvement in HCC patients with HCV cure. ${ }^{11-13}$

For cirrhotic patients with early-stage HCC within Milan criteria, liver transplantation (LT) remains the gold-standard curative treatment option. ${ }^{14}$ In the U.S., an estimated 900 liver transplants are performed each year for HCV-associated HCC. ${ }^{15}$ In light of controversial data suggesting DAAs may accelerate HCC recurrence and the paucity of data investigating the impact of timing of DAAs in the setting of liver transplantation, there is significant practice pattern variability across the country for when DAAs are administered, either pre or post-LT. Thus, we sought to assess the optimal timing of DAAs in patients with HCVassociated $\mathrm{HCC}$ who underwent liver transplantation.

\section{Methods}

\section{Study Design and Study Population}

In this retrospective cohort study, patients were selected from the U.S. Hepatocellular Carcinoma Liver Transplantation Consortium (US-HCC-LTC), a multi-institutional collaborative of 20 high-volume liver transplant centers, including Emory University, the University of Cincinnati College of Medicine, David Geffen School of Medicine at University of California Los Angeles, Johns Hopkins, Oregon Health and Science University, 
Indiana University Health, University of Alabama at Birmingham, Lahey Hospital and Medical Center, Keck Hospital of University of Southern California, Cleveland Clinic, University of Texas Southwestern Medical Center, Stanford University Medical Center, Tampa General Hospital, Piedmont Healthcare, University of Michigan, University of Wisconsin School of Medicine in Madison, Duke University School of Medicine, Henry Ford Health System, University of Pittsburgh Medical Center, and Washington University School of Medicine in St. Louis. Patients who were older than 18 years of age with a diagnosis of $\mathrm{HCC}$ due to $\mathrm{HCV}$ etiology, received DAA therapy, and underwent liver transplantation between 2015-2019 were included. HCC diagnosis was made according to the established Barcelona Clinic Liver Cancer Guidelines. HCV diagnosis was defined by the presence of HCV antibody or HCV RNA. Patients who had missing DAA timing data, who had gross residual disease at the time of surgery (R2), who were transplanted outside of Milan criteria, or who previously received interferon therapy were excluded from final analysis. Institutional Review Board approval was obtained at each center prior to the initiation of data collection.

\section{Study Variables and Outcomes}

Demographic, preoperative, operative, post-operative, histopathologic, and long-term survival outcomes were collected via review of each patient's electronic medical record. DAA therapy timing was categorized as the initiation of DAA therapy pre-LT, 0-3 months post-LT, or $\geq 3$ months post-LT. Liver-directed therapy included radiofrequency ablation (RFA), transarterial chemoembolization (TACE), and/or Y-90. Primary outcomes were sustained virologic response (SVR) and HCC recurrence-free survival (RFS). Acute rejection included acute T-cell mediated (cellular) rejection or acute antibody-mediated rejection.

Analytic Plan

Statistical analysis was conducted with SPSS 26.0 software (IBM Inc., Armonk, NY). Descriptive statistics for each variable are reported. A significance level (alpha) of 0.05 was specified for two-tailed tests. Comparative analysis was performed, including Chi-squared tests or Fisher's exact tests for discrete variables and Student's t-test or Mann-Whitney tests for continuous variables. Univariate binary logistic regression was performed to determine the association of clinicopathologic variables and outcomes of interest. Kaplan-Meier logrank analysis and Cox regression were performed to determine the association between timing of DAA therapy and HCC RFS.

\section{Results}

\section{Study Cohort Characteristics}

Of the 857 patients in the US-HCC-LTC, 427 met the specified inclusion criteria. Baseline demographic, clinicopathologic, perioperative, and oncologic data are outlined in Table 1. Fifty-eight percent $(\mathrm{n}=258)$ of patients received DAAs pre-LT, $10 \%(\mathrm{n}=45)$ received DAAs $0-3$ months post-LT, and $27 \%(\mathrm{n}=124)$ received DAAs $\geq 3$ months post-LT. The 
median age at diagnosis was 61 years. A higher proportion of patients received ledipasvir/sofosbuvir compared to a sofosbuvir/velpatasvir or glecaprevir/pibrentasvir regimen. While the majority of patients underwent liver-directed therapy prior to LT, a higher proportion received liver-directed therapy if DAAs were administered pre-LT $(93 \%, \mathrm{n}=241)$, compared to those who received DAAs $0-3$ months post-LT $(89 \%, n=40)$ or $\geq 3$ months postLT at $(82 \%, n=102)$. Patients who received DAAs post-LT were more likely to receive an $\mathrm{HCV}+$ donor liver, with $36 \%(\mathrm{n}=16)$ of patients receiving $\mathrm{HCV}+$ livers in the $0-3$ months post-LT group and $33 \%(n=40)$ in the $\geq 3$ months post-LT group, compared to $4 \%(n=9)$ in the pre-LT group. Notably, post-operative complication rates did not differ between the DAA timing groups ( $42 \%$ pre-LT, $53 \% 0-3$ months post-LT, $48 \% \geq 3$ months post-LT, $\mathrm{p}=0.25$ ). A higher rate of acute rejection was seen in the patients who received DAAs $0-3$ months postLT $(27 \%, n=12)$, compared to those who received DAAs pre-LT $(13 \%, n=34)$ and $\geq 3$ months post-LT $(8 \%, \mathrm{n}=10)$. The median time on the waitlist was 7 months (interquartile range, IQR 3-12). Median follow-up from liver transplant was 36 months (IQR 21-52).

\section{Sustained Virologic Response}

For patients within Milan criteria who were interferon-treatment naïve, receiving DAA therapy $\geq 3$ months post-LT was associated with a decreased odds of achieving SVR (OR 0.36, 95\% CI 0.20-0.65, $\mathrm{p}<0.01$ ) (Table 2). Patients who received DAAs pre-LT, 0-3 months post-LT, and $\geq 3$ months post-LT achieved SVR rates of $91 \%, 93 \%$, and $78 \%$, respectively. Notably, patients who received DAAs pre and 0-3mo post-transplant had nearly a $15 \%$ increased rate of SVR compared to those who received DAAs $\geq 3$ months posttransplant.

Of the 725 patients within Milan criteria, regardless of prior HCV treatment, patients who received DAAs pre and 0-3 months post-LT had an increased rate of SVR of $91 \%$ and $92 \%$, compared to $82 \%$ for those who received DAAs $\geq 3$ months post-transplant $(p<0.01)$.

\section{HCC Recurrence-Free Survival}

Receiving DAA therapy $\geq 3$ months post-LT was associated with worse RFS on univariate Cox regression (HR 2.34, 95\% CI 1.14-4.82, $\mathrm{p}=0.02$ ) (Table 3). Factors associated with improved RFS included achieving SVR (HR 0.28, 95\% CI 0.13-0.62, $\mathrm{p}<0.01$ ) and a ledipadsvir/sofosbuvir DAA regimen (HR 0.33, 95\% CI 0.13-0.84, p<0.01). Prior liverdirected therapy was not associated with RFS.

Considering patients within Milan criteria who were interferon-treatment naïve, achieving SVR with DAAs was associated with improved 5-year RFS at $93 \%$, compared to $76 \%$ in those who did not achieve SVR (Figure 1). Receiving DAAs 0-3 months post-LT was associated with an improved 5-year RFS of $100 \%$ compared to those who received DAAs pre-LT at $93 \%$, and $83 \%$ for those who received DAAs $\geq 3$ months post-LT (Figure 2). Administering DAAs in the early post-operative period (0-3 months) was associated with improved SVR and RFS. 
For patients meeting Milan criteria, including those who received prior $\mathrm{HCV}$ treatment, patients who received DAAs pre-LT, 0-3 months post-LT, and $\geq 3$ months had 5year RFS of $93 \%, 94 \%$, and $87 \%$, respectively $(\mathrm{p}=0.15)$.

\section{Discussion}

For interferon treatment-naïve patients with $\mathrm{HCV}$-associated $\mathrm{HCC}$ within Milan criteria undergoing liver transplantation, our analysis of a large multi-institutional collaborative of 20 high-volume centers in the U.S. demonstrates that administering DAAs in the early post-operative period, specifically within 3 months of liver transplantation, is associated with improved rates of achieving sustained virologic response and increased HCC recurrence-free survival.

Prior to 2011, treatment for HCV was severely limited, as the only available option was interferon-based therapy. Unfortunately, given suboptimal efficacy and significant adverse drug reactions, interferon was poorly tolerated, leading to poor compliance and modest SVR rates ranging from $29-56 \%{ }^{16,17}$ The emergence of DAAs fundamentally changed the HCV treatment landscape by offering a simple one pill per day dosing with minimal side effects, allowing patients to achieve SVR rates of $95-97 \% .{ }^{18}$ As a result, patients benefited from marked improvement in liver-associated morbidity and mortality. A 2017 retrospective review of 22,500 patients with HCV reported achieving SVR with DAAs resulted in a significantly reduced risk of developing de novo HCC (HR 0.28, 95\% CI 0.220.36). ${ }^{19}$ In addition, a more recent study from our group demonstrated the association of HCV treatment with improved long-term outcomes in patients treated for HCC, regardless of clinical stage, HCC treatment modality, or treatment facility type. ${ }^{20}$ However, it is important to note that the high SVR rates often quoted is derived from studies that include patients with HCV who do not have active HCC. Patients with active HCC seem to achieve significant lower rates of SVR compared to non-HCC patients. In fact, a recent meta-analysis published in 2019 reported SVR rates with DAA therapy in the presence of active HCC was as low as $73 \% .^{21}$ The investigators also determined SVR rates were higher in patients who underwent curative-intent treatments of their HCC prior to receiving DAA therapy. Although the exact mechanism for this observation is not fully understood, HCC may function as a reservoir for $\mathrm{HCV}$ replication. Regardless, with the considerable success of DAAs, interferon-based treatment strategies are no longer relevant to the modern management of HCV. Hence, for this study, we focused on an interferon treatment-naïve patient population. Furthermore, by excluding patients with prior interferon therapy, we removed a potential confounder for the immunologic interaction between $\mathrm{HCV}, \mathrm{HCC}$, and transplant immunosuppression, to better isolate the DAA timing question.

Considering the multiple treatment approaches for $\mathrm{HCC}$, complete tumor extirpation, specifically resection or liver transplantation, are the preferred curative treatment options, with the latter resulting in the most favorable long-term outcomes. ${ }^{22}$ While the appropriate treatment strategy is dependent on the tumor burden, liver function, renal function, ChildPugh status, and the future liver remanent, liver transplantation not only allows for clearance 
of the tumor, but also addresses any underlying liver disease. Other treatment modalities, including liver-directed therapy, radiation therapy, and systemic therapy, are often employed in combination with resection or as a bridge to liver transplant. ${ }^{23}$ Given patients within Milan criteria are on the waitlist for an average of 8.4 months, many are offered bridging therapy to transplant with the goal of preventing disease progression beyond Milan criteria. ${ }^{24}$ Predictably, liver-directed therapies are more frequently employed in liver transplant patients compared to other HCC patients. ${ }^{25}$ Our data supports this trend. Nonetheless, compared to all other treatment approaches for unresectable disease, liver transplant offers superior oncologic outcomes in well-selected patients, with 5 -year overall survival surpassing $70 \%{ }^{26}$

Recent reports have described the immunomodulatory effect of DAAs in the context of HCC and liver transplant. HCV is known to induce hepatocyte apoptosis, oxidative stress, and steatosis, resulting in progressive liver damage, fibrosis, and ultimately end-stage liver disease. ${ }^{27}$ The 3 main classes of DAAs work by inhibiting specific HCV non-structural proteins involved in viral replication, namely NS3/4A, NS5A, and NS5B. ${ }^{28}$ While most do not consider DAAs themselves tumorigenic, DAAs may increase the risk for de novo HCC or recurrence via an indirect mechanism. After eradication of the virus, DAA therapy evokes profound immunological changes. Specifically, DAAs rapidly decrease the cytotoxic function of natural killer (NK) cells and mucosal-associated invariant $\mathrm{T}$ (MAIT) cells, dampen intrahepatic activation of macrophages, and increase frequencies of suppressive regulatory $\mathrm{T}$ cells and myeloid-derived suppressor cells (MDSCs). ${ }^{29}$ The downstream effects of this are the creation of a persistent immunosuppressed state with ineffective tumor surveillance mechanisms.

Offering DAA therapy prior to liver transplant allows for the treatment of HCV while the patient is on the waitlist, which reduces chronic hepatitis and may improve liver function. ${ }^{34}$ Improvements in liver function due to DAA therapy, however, have not been shown to significantly impact waitlist priority or dropout rates. ${ }^{35,36}$ Further, HCV exposure to the liver transplant surgical team is dramatically reduced. A potential disadvantage for administering DAA therapy prior to liver transplant in the setting of HCC includes decreased rates of SVR, as the presence of HCC tumors may serve as a reservoir for HCV. ${ }^{21}$ This increases the risk for treatment failure and promotes resistance to re-treatment, which requires additional courses of DAAs, leading to an excess of $\$ 25,000-70,000$ in costs compared to those who receive DAAs post-LT. ${ }^{37,38}$

Conversely, reserving DAA therapy until after liver transplant may be preferred based on data demonstrating the improved efficacy of DAAs in achieving SVR, as well as a potential for a decreased risk of recurrence of HCC. ${ }^{39}$ Further, treating HCV post-transplant increases access to HCV-positive donors, as HCV-positive livers comprise 3-15\% of donor pools across United Network for Organ Sharing (UNOS) regions. ${ }^{40}$ Admittedly, this may be less of a clinical concern given recent experiences with transplanting HCV-positive organs into HCV-negative hosts. Consistent with prior literature, our study demonstrates initiating DAA therapy 0-3 months post-LT was associated with high rates of SVR. Remarkably, among the 20 liver transplant centers included in this consortium, only a minority of patients 
(10\%) received DAAs 0-3 months post-LT. While post-operative complications may lead to a delay in initiating DAA therapy, it is worth noting there was no significant difference in postoperative complication rates between the DAA timing groups. In fact, the post-operative complication rates were slightly higher in the $0-3$ months post-LT group, compared to the pre-LT and $\geq 3$ months post-LT groups.

With the widespread use of DAAs, controversial data have emerged suggesting an increased risk of recurrent HCC following DAA therapy. Reig et al. reported a high rate of early HCC recurrence of $35 \%$ in 20 patients treated with DAAs who underwent resection or received liver-directed therapy. ${ }^{9}$ Comparably, 19 patients receiving DAAs had an HCC recurrence rate of $42.1 \%$ in a study conducted by Conti and colleagues. ${ }^{10}$ These findings may be confounded by a small sample size and lack of a comparison group. More recent studies have not observed an association between DAA administration and HCC recurrence. ${ }^{11,41-46} \mathrm{~A}$ 2017 meta-analysis by Waziry et al. suggested there was no evidence for increased HCC recurrence after SVR was achieved from DAA or interferon-based therapy, however, the impact of timing of therapy as a variable was not taken into consideration. ${ }^{12}$ The above conflicting literature highlight the significant heterogeneity of study inclusion criteria, HCC treatment modalities, and $\mathrm{HCV}$ treatment regimens.

Currently, there is limited data regarding the optimal time to initiate DAAs in the liver transplant population. ${ }^{47,48} \mathrm{~A}$ study by Gorgen et al. sought to answer this question among 516 patients with underwent liver transplantation for HCV with concomitant HCC who received DAA therapy either pre or post-LT. ${ }^{49}$ The investigators reported an SVR rate of $93.4 \%$ and a 5-year RFS of $93.4 \%$ for patients who received DAAs pre-LT and an SVR rate of $96.5 \%$ and a recurrence rate of $2.9 \%$ for those who received DAAs post-LT. However, the study time period included patients from 2005-2015, while DAAs were only widely disseminated in 2015. In addition, a number of patients were transplanted outside of Milan criteria $(9.1 \%$ preLT, $17.2 \%$ post-LT) and the median time interval between administration of DAAs and liver transplant was 2.4 months for pre-LT and 24 months post-LT. The comparison groups also included patients who received interferon, a now outdated form of treatment. Our study, in contrast, sought to determine the optimal timing of DAA therapy in the modern era of $\mathrm{HCV}$ treatment in an interferon treatment-naïve patient population.

Limitations of this study include those inherent in a retrospective design, specifically the exclusion of missing data. Second, the event rate for recurrence was zero for the patients who received DAAs 0-3 months post-LT, limiting our ability to perform multivariable analysis, and the sample size was small in that timing group. However, the fact that there were no events is very striking and warrants further investigation. Third, as this study represents real-world practice patterns, there is variability between institutions regarding DAA regimen, pre-LT therapy, post-LT immunosuppression, and surveillance protocols for HCC recurrence. Fourth, data on specific HCV genotype was not available.

A major strength of this study is mitigation of single-institution or single-provider bias with a consortium of 20 transplant centers in the U.S. Second, the isolation of our 
exposure of interest, the timing of DAA therapy, was improved as a result of our selected inclusion criteria for liver transplant patients with $\mathrm{HCV}$-associated $\mathrm{HCC}$ who were interferon treatment-naïve and within Milan criteria. Thus, we were able to limit potential biological confounders and better control for immunologic and oncologic variability. Third, the rates of SVR and RFS represent real-world data from among the highest volume liver transplant centers in the U.S. Lastly, the findings of this study provide clinicians with valuable insights that can be readily applied to clinical practice, although further investigation into the immunologic mechanism is needed.

\section{Conclusions}

In summary, the optimal timing of DAA therapy appears to be 0-3 months after liver transplant for $\mathrm{HCV}$-associated $\mathrm{HCC}$, given increased rates of sustained virologic response and improved HCC recurrence-free survival. Importantly, delayed administration of DAAs more than 3 months after liver transplant should be avoided as it is possible that induction of immunosuppression post-transplant in combination with prolonged exposure to $\mathrm{HCV}$ and an exaggerated state of $\mathrm{T}$ cell impairment created by the late administration of DAA therapy may lead to increased HCC recurrence. A randomized prospective trial is warranted to validate these findings.

\section{Acknowledgements}

The authors also thank the Katz Foundation and the National Center for Advancing Translational Science, Grant/Award Number: UL1TR002378/TL1TR002382.

\section{DISCUSSANT}

\section{Dr. Robert A. Montgomery:}

I want to thank the ASA and meeting organizers for inviting me to comment on the paper entitled, "Optimal Timing of Direct Acting Antivirals for Patients with Hepatitis CAssociated Hepatocellular Carcinoma Undergoing Liver Transplantation” which was nicely presented by Dr. Michael Turgeon.

The authors report data from the HCC Liver Transplantation Consortium looking at the timing of DAA treatment among patients who underwent liver transplantation between 2015 and 2019. The primary outcomes were sustained viral response and 5-year HCC recurrencefree survival. The major finding was that the optimal timing for DAA therapy was 0-3 months post-transplantation and delaying treatment beyond 3 months was associated with worse outcomes.

Question \#1 for the investigators is why were the overall SVR rates lower than expected for pan-genotypic DAAs that have cited cure rates exceeding $95 \%$ ? 
Question \#2 when SVR was not achieved was there a dominant genotype or DAA regimen associated with incomplete response?

\section{Response Dr. Shishir K. Maithel}

Thank you Drs. Deveney and Drebin. On behalf of all our co-authors, I would first like to thank the American Surgical for the privilege of presenting our study today. It is also truly an honor to have Dr. Montgomery review and comment on our paper. I would also like to acknowledge Dr. Michael Turgeon, a general surgery resident at Emory, for all of his hard work leading this large multi-institutional study and thank Drs. Shimul Shah and Will Chapman for co-leading this study with us.

I will first address Dr. Montgomery's question regarding the overall SVR rates being lower than expected. The $95-97 \%$ cure rate that is often quoted is derived from studies that include patients with HCV who do not have HCC. Patients with active HCC seem to achieve significantly lower rates of SVR compared to non-HCC patients. In fact, a recent metaanalysis published in 2019 by one of our co-authors, Dr. Mindie Nguyen from Stanford University, reported that the SVR rates with DAA therapy in the presence of active HCC was as low as $73 \%$. They also found that SVR rates were higher in patients who underwent curative intent treatments of their HCC prior to receiving DAA therapy. Although the exact mechanism for this observation is not fully understood, hepatocellular carcinoma may function as a reservoir for $\mathrm{HCV}$ replication. Further, the usual associated cirrhosis that is present in patients who have HCV and HCC may lead to impaired innate and adaptive immune responses due to reduced cytotoxicity of natural killer cells and $\mathrm{T}$ cell exhaustion, leading to suboptimal SVR rates in these patients.

With regards to the second question regarding genotypes, we unfortunately did not have the granularity of specific genotypes in our database, so that is definitely a limitation of this study. Given the time frame of our study from $2015-2019,50 \%$ of the patients received Harvoni. Since genotypes 1 and 2 comprise the vast majority of HCV infections, despite Harvoni not having activity against Genotype 3, which makes up only $10-12 \%$ of infections, the SVR rate for Harvoni was $88 \%$. Epclusa had an SVR rate of $94 \%$ and interestingly Mavyret had the lowest SVR rate of 79\%. Despite these small differences in SVR rates between the three most common regimens, on binary logistic regression analysis, it is important to note that no one regimen was significantly associated with a lower SVR rate.

Clearly, the interaction between Hepatitis $\mathrm{C}$ virus, hepatocellular carcinoma, post-transplant immunosuppression, and DAA therapy is very complex and affects both the success of DAA therapy in achieving SVR, and the success of liver transplantation in achieving cure of HCC. Furthermore, achieving SVR seems to also be associated with improved oncologic outcomes for HCC as well. Thus, we strongly feel that the optimal timing of DAA therapy needs to be studied in a prospective clinical trial and the underlying immunologic mechanisms that drive these clinical observations need to be studied and understood. 
Again, thank you to the American Surgical Association for the privilege of presenting our work today.

\section{References}

1. Kim HS, El-Serag HB. The Epidemiology of Hepatocellular Carcinoma in the USA. Curr Gastroenterol Rep. Apr 11 2019;21(4):17. doi:10.1007/s11894-019-0681-x

2. White DL, Thrift AP, Kanwal F, Davila J, El-Serag HB. Incidence of Hepatocellular Carcinoma in All 50 United States, From 2000 Through 2012. Gastroenterology. Mar 2017;152(4):812-820 e5. doi:10.1053/j.gastro.2016.11.020

3. Ghouri YA, Mian I, Rowe JH. Review of hepatocellular carcinoma: Epidemiology, etiology, and carcinogenesis. J Carcinog. 2017;16:1. doi:10.4103/jcar.JCar_9_16

4. González-Grande R, Jiménez-Pérez M, González Arjona C, Mostazo Torres J. New approaches in the treatment of hepatitis $\mathrm{C}$. World journal of gastroenterology. 2016;22(4):1421-1432. doi:10.3748/wjg.v22.i4.1421

5. González-Grande R, Jiménez-Pérez M, González Arjona C, Mostazo Torres J. New approaches in the treatment of hepatitis C. World J Gastroenterol. Jan 28 2016;22(4):1421-32. doi:10.3748/wjg.v22.i4.1421

6. El-Serag HB. Epidemiology of viral hepatitis and hepatocellular carcinoma. Gastroenterology. 2012;142(6):1264-1273.e1. doi:10.1053/j.gastro.2011.12.061

7. Garcia-Pajares F, Tejedor-Tejada J, Torres-Yuste R, et al. Efficacy of Direct-acting Antivirals to Improve Clinical Condition, Fibrosis, and Liver Function in Liver Transplant Recipients Infected by Hepatitis C. Transplant Proc. Jan-Feb 2019;51(1):74-76. doi:10.1016/j.transproceed.2018.04.088

8. Calvaruso V, Cabibbo G, Cacciola I, et al. Incidence of Hepatocellular Carcinoma in Patients With HCV-Associated Cirrhosis Treated With Direct-Acting Antiviral Agents. Gastroenterology. Aug 2018;155(2):411-421.e4. doi:10.1053/j.gastro.2018.04.008

9. Reig M, Marino Z, Perello C, et al. Unexpected high rate of early tumor recurrence in patients with HCV-related HCC undergoing interferon-free therapy. J Hepatol. Oct 2016;65(4):719-726. doi:10.1016/j.jhep.2016.04.008 
10. Conti F, Buonfiglioli F, Scuteri A, et al. Early occurrence and recurrence of hepatocellular carcinoma in $\mathrm{HCV}$-related cirrhosis treated with direct-acting antivirals. J Hepatol. Oct 2016;65(4):727-733. doi:10.1016/j.jhep.2016.06.015

11. Singal AG, Rich NE, Mehta N, et al. Direct-Acting Antiviral Therapy Not Associated With Recurrence of Hepatocellular Carcinoma in a Multicenter North American Cohort Study. Gastroenterology. May 2019;156(6):1683-1692.e1. doi:10.1053/j.gastro.2019.01.027

12. Waziry R, Hajarizadeh B, Grebely J, et al. Hepatocellular carcinoma risk following direct-acting antiviral HCV therapy: A systematic review, meta-analyses, and metaregression. J Hepatol. Dec 2017;67(6):1204-1212. doi:10.1016/j.jhep.2017.07.025

13. Singal AG, Rich NE, Mehta N, et al. Direct-Acting Antiviral Therapy for Hepatitis C Virus Infection Is Associated With Increased Survival in Patients With a History of Hepatocellular Carcinoma. Gastroenterology. Nov 2019;157(5):1253-1263.e2. doi:10.1053/j.gastro.2019.07.040

14. Mazzaferro V, Regalia E, Doci R, et al. Liver transplantation for the treatment of small hepatocellular carcinomas in patients with cirrhosis. N Engl J Med. Mar 14 1996;334(11):693-9. doi:10.1056/nejm199603143341104

15. Network OPaT. National Data. Accessed 2020, 2020. http://optn.transplant.hrsa.gov

16. Younossi ZM, Stepanova M, Henry L, Nader F, Younossi Y, Hunt S. Adherence to treatment of chronic hepatitis $\mathrm{C}$ : from interferon containing regimens to interferon and ribavirin free regimens. Medicine (Baltimore). Jul 2016;95(28):e4151. doi:10.1097/md.0000000000004151

17. Fried MW, Shiffman ML, Reddy KR, et al. Peginterferon alfa-2a plus ribavirin for chronic hepatitis C virus infection. N Engl J Med. Sep 26 2002;347(13):975-82. doi:10.1056/NEJMoa020047

18. Backus LI, Belperio PS, Shahoumian TA, Mole LA. Direct-acting antiviral sustained virologic response: Impact on mortality in patients without advanced liver disease. Hepatology. Sep 2018;68(3):827-838. doi:10.1002/hep.29811

19. Kanwal F, Kramer J, Asch SM, Chayanupatkul M, Cao Y, El-Serag HB. Risk of Hepatocellular Cancer in HCV Patients Treated With Direct-Acting Antiviral Agents. Gastroenterology. Oct 2017;153(4):996-1005.e1. doi:10.1053/j.gastro.2017.06.012

20. Turgeon MK, Lee RM, Gamboa AC, et al. Impact of hepatitis C treatment on longterm outcomes for patients with hepatocellular carcinoma: a United States Safety Net Collaborative Study. HPB (Oxford). Aug 7 2020;doi:10.1016/j.hpb.2020.07.012 
21. Ji F, Yeo YH, Wei MT, et al. Sustained virologic response to direct-acting antiviral therapy in patients with chronic hepatitis $\mathrm{C}$ and hepatocellular carcinoma: A systematic review and meta-analysis. Journal of Hepatology. 2019/09/01/ 2019;71(3):473-485. doi:https://doi.org/10.1016/j.jhep.2019.04.017

22. Forner A, Reig M, Bruix J. Hepatocellular carcinoma. Lancet. Mar 31 2018;391(10127):1301-1314. doi:10.1016/s0140-6736(18)30010-2

23. Lurje I, Czigany Z, Bednarsch J, et al. Treatment Strategies for Hepatocellular Carcinoma $^{-}$a Multidisciplinary Approach. International journal of molecular sciences. 2019;20(6):1465. doi:10.3390/ijms20061465

24. Mehta N, Heimbach J, Lee D, et al. Wait Time of Less Than 6 and Greater Than 18 Months Predicts Hepatocellular Carcinoma Recurrence After Liver Transplantation: Proposing a Wait Time "Sweet Spot". Transplantation. 2017;101(9):2071-2078. doi:10.1097/TP.0000000000001752

25. Rahimi RS, Trotter JF. Liver transplantation for hepatocellular carcinoma: outcomes and treatment options for recurrence. Annals of gastroenterology. Jul-Sep 2015;28(3):323-330.

26. Kow AWC. Transplantation versus liver resection in patients with hepatocellular carcinoma. Translational gastroenterology and hepatology. 2019;4:33-33. doi:10.21037/tgh.2019.05.06

27. Irshad M, Gupta P, Irshad K. Molecular basis of hepatocellular carcinoma induced by hepatitis C virus infection. World journal of hepatology. 2017;9(36):1305-1314. doi:10.4254/wjh.v9.i36.1305

28. Geddawy A, Ibrahim YF, Elbahie NM, Ibrahim MA. Direct Acting Anti-hepatitis C Virus Drugs: Clinical Pharmacology and Future Direction. Journal of translational internal medicine. 2017;5(1):8-17. doi:10.1515/jtim-2017-0007

29. Sung PS, Shin E-C. Immunological Mechanisms for Hepatocellular Carcinoma Risk after Direct-Acting Antiviral Treatment of Hepatitis C Virus Infection. Journal of clinical medicine. 2021;10(2):221. doi:10.3390/jcm10020221

30. Filgueira NA. Hepatocellular carcinoma recurrence after liver transplantation: Risk factors, screening and clinical presentation. World journal of hepatology. 2019;11(3):261-272. doi:10.4254/wjh.v11.i3.261

31. Verna EC, Patel YA, Aggarwal A, et al. Liver transplantation for hepatocellular carcinoma: Management after the transplant. Am J Transplant. Feb 2020;20(2):333347. doi:10.1111/ajt.15697 
32. Nault JC, Colombo M. Hepatocellular carcinoma and direct acting antiviral treatments: Controversy after the revolution. J Hepatol. Oct 2016;65(4):663-665. doi:10.1016/j.jhep.2016.07.004

33. Langhans B, Nischalke HD, Krämer B, et al. Increased peripheral CD4(+) regulatory $\mathrm{T}$ cells persist after successful direct-acting antiviral treatment of chronic hepatitis $\mathrm{C}$. J Hepatol. May 2017;66(5):888-896. doi:10.1016/j.jhep.2016.12.019

34. Harrod E, Moctezuma-Velazquez C, Gurakar A, Ala A, Dieterich D, Saberi B. Management of concomitant hepatocellular carcinoma and chronic hepatitis C: a review. Hepatoma Research. 2019;5:28. doi:10.20517/2394-5079.2019.15

35. Huang AC, Mehta N, Dodge JL, Yao FY, Terrault NA. Direct-acting antivirals do not increase the risk of hepatocellular carcinoma recurrence after local-regional therapy or liver transplant waitlist dropout. Hepatology (Baltimore, Md). 2018;68(2):449-461. doi:10.1002/hep.29855

36. Emamaullee JA, Bral M, Meeberg G, et al. HCV Eradication with Direct-Acting Antivirals Does Not Impact HCC Progression on the Waiting List or HCC Recurrence after Liver Transplantation. Canadian Journal of Gastroenterology and Hepatology. 2019/01/17 2019;2019:2509059. doi:10.1155/2019/2509059

37. Paolucci S, Fiorina L, Mariani B, et al. Development and persistence of DAA resistance associated mutations in patients failing HCV treatment. J Clin Virol. Nov 2015;72:114-8. doi:10.1016/j.jcv.2015.08.015

38. Khan AS, Adams N, Vachharajani N, et al. Liver transplantation for hepatitis C patients in the era of direct-acting antiviral treatment: A retrospective cohort study. Int J Surg. Mar 2020;75:84-90. doi:10.1016/j.ijsu.2020.01.145

39. Prenner SB, Kulik L. Hepatocellular carcinoma in the wait-listed patient with hepatitis C virus. Curr Opin Organ Transplant. Apr 2018;23(2):237-243. doi:10.1097/mot.0000000000000505

40. Salazar J, Saxena V, Kahn JG, et al. Cost-Effectiveness of Direct-Acting Antiviral Treatment in Hepatitis C-Infected Liver Transplant Candidates With Compensated Cirrhosis and Hepatocellular Carcinoma. Transplantation. 2017;101(5):1001-1008. doi:10.1097/TP.0000000000001605

41. Zavaglia $\mathrm{C}$, Okolicsanyi $\mathrm{S}$, Cesarini $\mathrm{L}$, et al. Is the risk of neoplastic recurrence increased after prescribing direct-acting antivirals for HCV patients whose HCC was previously cured? J Hepatol. Jan 2017;66(1):236-237. doi:10.1016/j.jhep.2016.08.016 
42. Kolly P, Waidmann O, Vermehren J, et al. Hepatocellular carcinoma recurrence after direct antiviral agent treatment: A European multicentre study. J Hepatol. Oct 2017;67(4):876-878. doi:10.1016/j.jhep.2017.07.007

43. Virlogeux V, Pradat P, Hartig-Lavie K, et al. Direct-acting antiviral therapy decreases hepatocellular carcinoma recurrence rate in cirrhotic patients with chronic hepatitis $\mathrm{C}$. Liver Int. Aug 2017;37(8):1122-1127. doi:10.1111/liv.13456

44. Nagata H, Nakagawa M, Asahina Y, et al. Effect of interferon-based and -free therapy on early occurrence and recurrence of hepatocellular carcinoma in chronic hepatitis C. J Hepatol. Nov 2017;67(5):933-939. doi:10.1016/j.jhep.2017.05.028

45. Imai K, Takai K, Hanai T, Suetsugu A, Shiraki M, Shimizu M. Sustained virological response by direct-acting antivirals reduces the recurrence risk of hepatitis $\mathrm{C}$-related hepatocellular carcinoma after curative treatment. Mol Clin Oncol. Feb 2020;12(2):111-116. doi:10.3892/mco.2019.1956

46. Gao X, Zhan M, Wang L, Ding Y, Niu J. Timing of DAA Initiation After Curative Treatment and Its Relationship with the Recurrence of HCV-Related HCC. J Hepatocell Carcinoma. 2020;7:347-360. doi:10.2147/jhc.S279657

47. Yang JD, Aqel BA, Pungpapong S, Gores GJ, Roberts LR, Leise MD. Direct acting antiviral therapy and tumor recurrence after liver transplantation for hepatitis Cassociated hepatocellular carcinoma. J Hepatol. Oct 2016;65(4):859-860. doi:10.1016/j.jhep.2016.06.023

48. Cholankeril G, Joseph-Talreja M, Perumpail BJ, et al. Timing of Hepatitis C Virus Treatment in Liver Transplant Candidates in the Era of Direct-acting Antiviral Agents. J Clin Transl Hepatol. Dec 28 2017;5(4):363-367. doi:10.14218/jcth.2017.00007

49. Gorgen A, Galvin Z, Huang AC, et al. The Impact of Direct-acting Antivirals on Overall Mortality and Tumoral Recurrence in Patients With Hepatocellular Carcinoma Listed for Liver Transplantation: An International Multicenter Study. Transplantation. Oct 2020;104(10):2087-2096. doi:10.1097/tp.0000000000003115 
Figure 1: HCC recurrence-free survival by SVR for interferon-naïve patients with HCVassociated HCC within Milan criteria who underwent liver transplantation

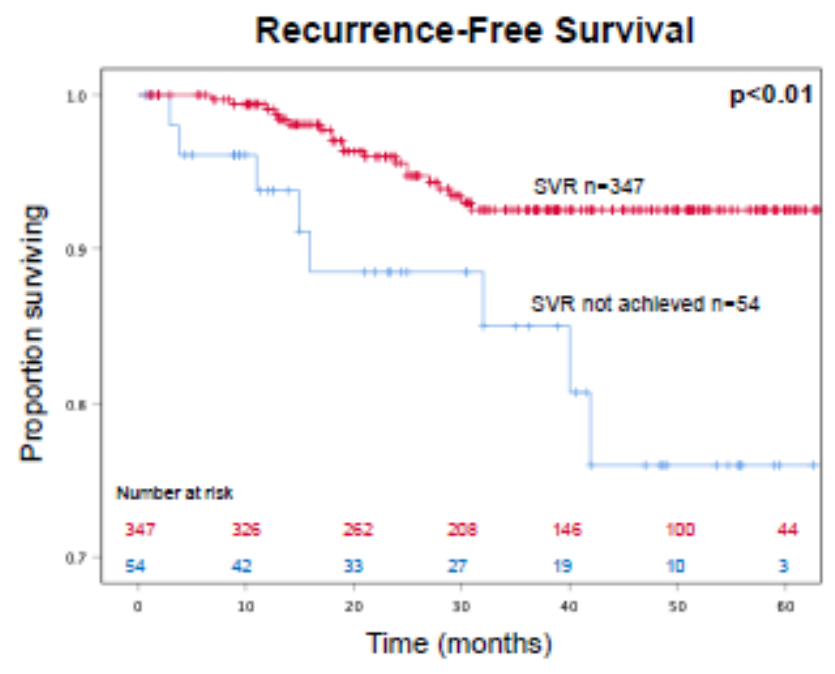

Figure 2: HCC recurrence-free survival by timing of DAA therapy initiation for interferonnaïve patients with $\mathrm{HCV}$-associated $\mathrm{HCC}$ within Milan criteria who underwent liver transplantation

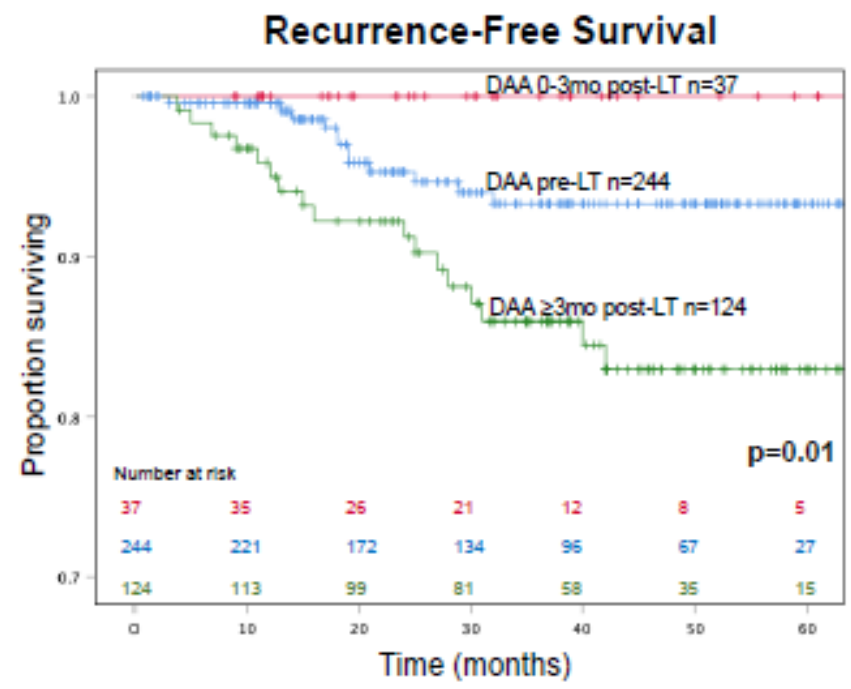

Copyright $\odot 2021$ Wolters Kluwer Health, Inc. Unauthorized reproduction of this article is prohibited. 
Table 1: Baseline characteristics for interferon-naïve patients with $\mathrm{HCV}$-associated HCC within Milan criteria who underwent liver transplantation

\begin{tabular}{|c|c|c|c|c|c|}
\hline Variable & $\begin{array}{l}\text { All Patients } \\
n=427(\%)\end{array}$ & $\begin{array}{c}\text { Pre-LT } \\
\text { n=258 (58) }\end{array}$ & $\begin{array}{l}\text { 0-3 months } \\
\text { Post-LT } \\
\text { n=45 (10) }\end{array}$ & $\begin{array}{l}\geq 3 \text { months } \\
\text { Post-LT } \\
\text { n=124 (27) }\end{array}$ & $\begin{array}{c}\text { p- } \\
\text { value }\end{array}$ \\
\hline Age at diagnosis (median, IQR) & $61(57-65)$ & $61(57-66)$ & $62(60-66)$ & $61(57-64)$ & 0.60 \\
\hline \multicolumn{6}{|l|}{ Gender } \\
\hline Female & $85(20)$ & $54(21)$ & $7(16)$ & $24(19)$ & 0.70 \\
\hline Male & $342(80)$ & $204(79)$ & $38(84)$ & $100(81)$ & \\
\hline \multicolumn{6}{|l|}{ Race } \\
\hline White & $273(64)$ & $160(62)$ & $27(61)$ & $86(69)$ & \multirow{5}{*}{0.47} \\
\hline Black & $72(17)$ & $45(17)$ & $10(22)$ & $17(14)$ & \\
\hline Asian & $14(3)$ & $11(4)$ & $0(0)$ & $3(2)$ & \\
\hline Latino & $64(15)$ & $41(16)$ & $7(16)$ & $16(13)$ & \\
\hline Other & $4(1)$ & $1(1)$ & $1(1)$ & $2(2)$ & \\
\hline \multicolumn{6}{|l|}{ ASA } \\
\hline I & $1(1)$ & & $0(0)$ & $0(0)$ & \multirow{4}{*}{0.10} \\
\hline II & $21(5)$ & $19(8)$ & $0(0)$ & $2(2)$ & \\
\hline III & $141(33)$ & $79(31)$ & $19(42)$ & $43(35)$ & \\
\hline IV & $256(61)$ & $151(60)$ & $26(58)$ & $79(63)$ & \\
\hline \multicolumn{6}{|l|}{ Functional status } \\
\hline Independent & $304(75)$ & $185(76)$ & $23(62)$ & $96(78)$ & \multirow{3}{*}{0.17} \\
\hline Partially dependent & $91(23)$ & $55(23)$ & $12(33)$ & $24(19)$ & \\
\hline Totally dependent & $9(2)$ & $3(1)$ & $2(5)$ & $4(3)$ & \\
\hline \multicolumn{6}{|l|}{ DAA regimen } \\
\hline Sofosbuvir/velpatasvir & $32(8)$ & $17(7)$ & $2(4)$ & $13(11)$ & \multirow{3}{*}{$<0.01$} \\
\hline Ledipasvir/sofosbuvir & $240(57)$ & $155(62)$ & $22(49)$ & $63(51)$ & \\
\hline Glecaprevir/pibrentasvir & $44(10)$ & $0(0)$ & $14(31)$ & $30(24)$ & \\
\hline
\end{tabular}




\begin{tabular}{|c|c|c|c|c|c|}
\hline Other & $104(25)$ & $79(31)$ & $7(16)$ & $18(14)$ & \\
\hline \multicolumn{6}{|l|}{ SVR achieved } \\
\hline No & $54(13)$ & $24(9)$ & $3(7)$ & $27(23)$ & $<0.01$ \\
\hline Yes & $365(87)$ & $231(91)$ & $41(93)$ & $93(77)$ & \\
\hline \multicolumn{6}{|l|}{ Received liver-directed therapy } \\
\hline \multicolumn{6}{|l|}{ No } \\
\hline \multirow[t]{2}{*}{ Yes } & $44(10)$ & $17(7)$ & $5(11)$ & & \\
\hline & $383(90)$ & $241(93)$ & $40(89)$ & $102(82)$ & \\
\hline \multicolumn{6}{|l|}{ Deceased donor } \\
\hline Deceased donor & $424(99)$ & $256(99)$ & $45(100)$ & $123(99)$ & 0.76 \\
\hline Living donor & $2(1)$ & $1(1)$ & $0(0)$ & $1(1)$ & \\
\hline \multicolumn{6}{|l|}{$\mathrm{HCV}+$ donor liver } \\
\hline No & $351(84)$ & & $28(64)$ & $81(67)$ & $<0.01$ \\
\hline Yes & $65(16)$ & $9(4)$ & $16(36)$ & $40(33)$ & \\
\hline \multicolumn{6}{|l|}{ Any post-operative complication } \\
\hline \multicolumn{6}{|l|}{ No } \\
\hline \multirow[t]{2}{*}{ Yes } & $236(55)$ & $150(58)$ & $21(47)$ & $65(52)$ & \\
\hline & $190(45)$ & $107(42)$ & $24(53)$ & $59(48)$ & \\
\hline \multicolumn{6}{|l|}{ Acute rejection } \\
\hline No & $371(87)$ & $224(87)$ & $33(73)$ & $114(92)$ & $<0.01$ \\
\hline Yes & $56(13)$ & $34(13)$ & $12(27)$ & $10(8)$ & \\
\hline \multicolumn{6}{|l|}{ Re-transplant } \\
\hline No & $420(99)$ & $253(98)$ & $44(98)$ & $123(99)$ & 0.75 \\
\hline Yes & $6(1)$ & $4(2)$ & $1(2)$ & $1(1)$ & \\
\hline Months on waitlist (median, IQR) & $7(3-12)$ & $8(4-14)$ & $7(2-8)$ & $8(4-7)$ & $<0.01$ \\
\hline Follow-up in months (median) & $36(21-52)$ & $34(18-51)$ & $30(19-44)$ & $41(28-54)$ & $<0.01$ \\
\hline
\end{tabular}


Table 2: Univariate binary logistic regression for achieving SVR for interferon-naïve patients with $\mathrm{HCV}$-associated HCC within Milan criteria who underwent liver transplantation

\begin{tabular}{|c|c|c|}
\hline & \multicolumn{2}{|c|}{ Logistic Regression } \\
\hline & OR $(95 \%$ CI $)$ & p-value \\
\hline Age at diagnosis (median, IQR) & $1.03(0.98-1.07)$ & 0.31 \\
\hline \multicolumn{3}{|l|}{ Gender } \\
\hline Female & Reference & \\
\hline Male & $0.46(0.19-1.11)$ & 0.08 \\
\hline \multicolumn{3}{|l|}{ Race } \\
\hline \multicolumn{3}{|l|}{ White } \\
\hline Black & $0.55(0.27-2.09)$ & 0.55 \\
\hline Asian & $+(0.22-13.75)$ & 1.74 \\
\hline Latino & $5(0.44-2.51)$ & 1.05 \\
\hline \multicolumn{3}{|l|}{ ASA } \\
\hline I & Reference & \\
\hline II & -- & -- \\
\hline III & -- & -- \\
\hline IV & -- & -- \\
\hline \multicolumn{3}{|l|}{ Functional status } \\
\hline Independent & Reference & \\
\hline Partially dependent & $1.18(0.58-2.40)$ & 0.65 \\
\hline Totally dependent & $1.14(0.14-9.46)$ & 0.91 \\
\hline \multicolumn{3}{|l|}{ DAA regimen } \\
\hline Sofosbuvir/velpatasvir & Reference & \\
\hline Ledipasvir/sofosbuvir & $0.48(0.11-2.11)$ & 0.33 \\
\hline
\end{tabular}




\begin{tabular}{|c|c|c|}
\hline Glecaprevir/pibrentasvir & $0.24(0.05-1.18)$ & 0.08 \\
\hline Other & $0.38(0.08-1.77)$ & 0.22 \\
\hline \multicolumn{3}{|l|}{ Timing of DAA therapy } \\
\hline Pre-LT & Reference & \\
\hline $0-3$ mo post-LT & $1.42(0.41-4.93)$ & \\
\hline$\geq 3 \mathrm{mo}$ post $\mathrm{LT}$ & $0.36(0.20-0.65)$ & $<0.01$ \\
\hline \multicolumn{3}{|c|}{ Received liver-directed therapy } \\
\hline \multicolumn{3}{|l|}{ No } \\
\hline Yes & $1.33(0.56-3.16)$ & 0.52 \\
\hline \multicolumn{3}{|l|}{ Deceased donor } \\
\hline \multicolumn{3}{|l|}{ Deceased donor } \\
\hline Living donor & -- & -- \\
\hline \multicolumn{3}{|l|}{$\mathrm{HCV}+$ donor liver } \\
\hline \multicolumn{3}{|c|}{ Reference } \\
\hline Yes & $0.65 .(0.31-1.34)$ & 0.24 \\
\hline \multicolumn{3}{|c|}{ Any post-operative complication } \\
\hline No & Reference & \\
\hline Yes & $0.60(0.34-1.07)$ & 0.08 \\
\hline \multicolumn{3}{|l|}{ Acute rejection } \\
\hline No & Reference & \\
\hline Yes & $1.47(0.56-3.87)$ & 0.44 \\
\hline \multicolumn{3}{|l|}{ Re-transplant } \\
\hline No & Reference & \\
\hline Yes & -- & \\
\hline Months on waitlist & $1.01(0.99-1.03)$ & 0.38 \\
\hline
\end{tabular}

Copyright $\odot 2021$ Wolters Kluwer Health, Inc. Unauthorized reproduction of this article is prohibited. 
Table 3: Univariate Cox regression for recurrence-free survival for interferon-naïve patients with HCV-associated HCC within Milan criteria who underwent liver transplantation

\begin{tabular}{|c|c|c|}
\hline & \multicolumn{2}{|c|}{ Cox Regression } \\
\hline & HR $(95 \%$ CI $)$ & p-value \\
\hline Age at diagnosis (median, IQR) & $0.99(0.94-1.05)$ & 0.83 \\
\hline \multicolumn{3}{|l|}{ Gender } \\
\hline Female & Reference & \\
\hline Male & $2.43(0.74-7$. & 0.14 \\
\hline \multicolumn{3}{|l|}{ Race } \\
\hline \multicolumn{3}{|l|}{ White } \\
\hline Black & $1.13(0.46-2.78)$ & 0.80 \\
\hline Asian & -- & -- \\
\hline Latino & $11(0.41-2.89)$ & 0.86 \\
\hline Other & -- & -- \\
\hline \multicolumn{3}{|l|}{ ASA } \\
\hline I & Reference & \\
\hline II & $1.38(0.17-10.86)$ & 0.76 \\
\hline III & $2.13(0.29-15.80)$ & 0.46 \\
\hline IV & -- & -- \\
\hline \multicolumn{3}{|l|}{ Functional status } \\
\hline Independent & Reference & \\
\hline Partially dependent & $0.36(0.11-1.19)$ & 0.09 \\
\hline Totally dependent & $1.83(0.44-7.71)$ & 0.41 \\
\hline \multicolumn{3}{|l|}{ DAA regimen } \\
\hline Sofosbuvir/velpatasvir & Reference & \\
\hline Ledipasvir/sofosbuvir & $0.33(0.13-0.84)$ & $<0.01$ \\
\hline Glecaprevir/pibrentasvir & $0.26(0.05-1.29)$ & 0.10 \\
\hline Other & $0.21(0.07-0.71)$ & $<0.01$ \\
\hline
\end{tabular}


Timing of DAA therapy

Pre-LT

Reference

0-3mo post-LT

$\geq 3$ mo post LT

SVR achieved

No

Yes

Received liver-directed therapy

No

Yes

Deceased donor

Deceased donor

Living donor

$\mathrm{HCV}+$ donor liver

No

Reference

Yes

\begin{tabular}{|c|c|c|}
\hline \multicolumn{3}{|c|}{ Any post-operative complication } \\
\hline No & Reference & \\
\hline Yes & $1.50(0.76-2.98)$ & 0.25 \\
\hline \multicolumn{3}{|l|}{ Acute rejection } \\
\hline No & Reference & \\
\hline Yes & $1.16(0.45-3.00)$ & 0.76 \\
\hline \multicolumn{3}{|l|}{ Re-transplant } \\
\hline No & Reference & \\
\hline Yes & $2.89(0.39-21.19)$ & 0.29 \\
\hline Months on waitlist & $0.97(0.93-1.02)$ & 0.19 \\
\hline
\end{tabular}

